\title{
Biographical Interview
}

\author{
Nuel Belnap
}

Abstract Biographical interview with Nuel Belnap, conducted in Utrecht, June 17 and 19, 2012. Interviewer: Thomas Müller. Edited, with the help of NB, in Pittsburgh, March 2013.

\section{School Days}

TM: Let's start with your school days. How many children were you at home?

NB: Four children. Three older sisters.

TM: Was it tough?

NB: No, amicable. Except of course there was this sister closest to me. We would have lots of arguments... what you do when you're young.

TM: And you lived near Chicago, for the whole time you went to school?

NB: Yes, we lived in Winnetka till I went to college. And then some. My parents still had the house, and they had a room for me.

TM: What was the school system like?

NB: Preschool when you were 5, in most cases. And first grade at 6. And, I was thinking about this yesterday when someone was talking about local customs, the rule was clearly that when you were in the first and second grade, you wore short pants.

\section{TM: Ok!}

NB: And then when you got to 3rd and 4th grade, you could wear knickers. In 5th grade you could wear long pants. Firm rules. They weren't even school rules, but everybody did it!

\footnotetext{
N. Belnap (凶)

1001 Cathedral of Learning, University of Pittsburgh, Pittsburgh, PA15260, U.S.A.

e-mail: belnap@pitt.edu
} 
TM: So no school uniform or anything ...

NB: No.

TM: And short pants even in the winter? Or how did that go?

NB: Yes, also in winter, but you had snow suits ...

TM: ... that you would put over for the walk to school?

NB: Yes. We didn't live very far from the school. Certainly no more than half a mile, but I don't remember how much less it was. Very close to the elementary school.

TM: And then that's 6 years, or how long did that go on for?

NB: Well, some people went on to junior high school in 6th grade - I did. And some in 7th. Junior high school is up to 8th grade, so that was 6th, 7th and 8th.

TM: And that was still close to where you lived?

NB: It was further, but it was surely less than a mile.

TM: That was already during the war, then?

NB: Well, it didn't begin during the war.-We had war bonds. I would go around with some kind of placard on my front and back that made fun of Adolf. The schools were excellent, they were nationally renowned, and progressive. Very much influenced by John Dewey.

TM: And did that mean coed?

NB: Oh yes, all schools were coed. But that went without saying, really, for public schools in that time period.

TM: And then, after you finished junior high?

NB: I went to high school. New Trier Township High School. And all those schools were really top-drawer. It was a wealthy suburb.

TM: So it was like that already then, that the school districts have a big influence on the value of property?

NB: Yes, that's true. I guess. I wasn't very much aware of the value of property.

TM: Did you get to pick special subjects, or was that a one size fits all idea?

NB: Not at all in grade school, and I don't think we had much choice in junior high either, there might have been some elective or something. But we had kind of a standard type of selection in high school, which is to say, ... there wasn't much you could do. And I don't really remember my selection principles at all.

TM: How was that with languages? Did you get to pick those yourself?

NB: Yes, you did get to pick your languages yourself. And I made a bad choice, I chose Spanish, because it was easy. And I learned what a mistake that was when I got to college and everyone learned French. I had to start over. But I learned a lot in high school. So much so that it really let me coast through about two years of college.

TM: That would mean you weren't really interested in many things that were happening in college because you'd had most of them, in a way?

NB: I guess. I don't remember my emotional structure. But I enjoyed high school. 
TM: You must have been very strong at math at that time.

NB: Yes, I took a lot of math, and I got good grades and everything. But no prizes. A lot of math, and I took the standard sciences, biology, chemistry, physics. I told you what I remember about my physics: An instructor who always said: "probably actually".

TM: And any ancient languages, was that at high school too?

NB: I did take Latin, for ... I think I only took it for a year. And that was hard. My languages were always very hard for me. I didn't work that hard at the Latin so I didn't learn much.

TM: Did you get any advice from school on what to pursue at college? I mean, the American college system is so much different from what I'm used to-in Germany the idea is more that you choose a subject from the start and that's what you will do your MA in.

NB: I know, it's not like that at all. The University of Illinois, like many colleges, had a program of a sort of general studies for freshmen and sophomores, and that's what I took. I didn't have to, but that's what I took.

TM: Like great books?

NB: I took great books in high school actually, and I loved it.

TM: That's a very nice idea, I think, to read great books in high school.

NB: Wrestling with Aristotle was the high point of my education, really. When I was a senior. The Ethics. So I sort of coasted through college as well-I was overprepared.

TM: That's how things go. So it wasn't really clear that it would be philosophy.

NB: No, I majored in philosophy for lack of anything else to do.

TM: Where there philosophy courses in high school, apart from the great books program?

NB: No.

TM: But that had some philosophy on it.

NB: Some, but ... well, we read some Shakespeare, a miscellaneous collection of great books. Later on when I was in Edgewood, a suburb of Pittsburgh, I taught great books at the third grade level. That was fun. Fairy stories, and what does it mean to be "born on a lucky day". We had fun. So then I went into the service, and really had no idea what I wanted to do, so I thought I had to pick out something. So I picked out going to graduate school in philosophy, after my two years of Air Force service.

TM: Where did that take you, the service?

NB: Oh that's when I programmed for the IBM 701 computer, in Washington. Six weeks in Texas getting basic training, crawling under the machine guns. But that wasn't much. And then Washington for two years. And my college girlfriend was in Washington as well, and so we got married. It was about like that! I had no idea what school to pick for grad school.

TM: Did you apply to several? 
NB: Yes I did, I don't remember which. Probably half a dozen or so, they all accepted. I picked out Yale because I had a first cousin that was in New Haven. That was what tipped the balance.

TM: It's like that, I think. Let's go back a little further, you said you had very good schools, but what about home-did you pick up an interest in books there?

NB: No, it wasn't a bookish family. I read all the time, of course ...

TM: ... but that was you.

NB: Yes. And my sisters did too. I don't remember too much about the older sisters, but certainly Dorothy read a lot too. But that came from the school.

TM: And the math interest, was there anything from home that would ring with that?

NB: Nothing at home at all. I joined the math club in high school.

TM: What did you get to do there?

NB: There's a presentation I remember. I went through this proof of $e^{i \pi}+1=0$. And I just read a bunch of general purpose books that had that in them, I was fascinated with it.

TM: I have heard that the American mathematics education is much different from what we get in Europe, in the sense that you get introduced to proofs rather late. How was that with you? Because now you're proving things all the time.

NB: I had only had proofs in geometry, Euclid.

TM: That was done, but ...

NB: ... but nothing else.

TM: So how did you learn to prove things?

NB: I guess, whatever, I don't know ... maybe I never did learn! I never had a course that asked for proofs.

TM: In logic then, in grad school, that's what you would do.

NB: Well, as a freshman, in the beginning logic of grad school we did proofs, of course. I meant to say the logic text I studied for my major was Cohen and Nagel. And I took a final examination of some kind, for honors in philosophy or something, and part of it was on logic. And what did they ask me ...? Something about syllogisms. And I hadn't a clue! I said, "I will be happy to answer this question if you explain the terminology", which they did.

TM: And then you could, I guess.

NB: Yes.

TM: Do you remember any teachers that were important for getting you somewhere academically? From the school days, I mean.

NB: I had a lot of good teachers, but is there any that stand out? I don't know. I remember Mr. Skarda did mathematics, and he said the one thing you're never gonna remember is what fraction 83 and a third is. And that was fixed firmly in my mind. And I had a good geometry teacher, Ms. Galley.

TM: So math and geometry were different subjects? 
NB: Geometry was a mathematics course, but it was a term devoted to geometry. In that sense a separate course. We never got into anything advanced, never got into even pre-calculus.

TM: Any probability theory, statistics?

NB: I guess elementary, but I don't remember too clearly. Or not at all maybe. We had algebra as freshmen, geometry as sophomore. And I had two more years of mathematics, but I can't remember exactly what they were. College algebra probably.

TM: So where did you learn set theory?

NB: Not in high school. Teaching it at Pitt.

TM: And you taught from Pat Suppes's book?

NB: I did. ... External to the school system, in the service, my boss was Thomas Steel, who was head of our section or whatever it was called. And he asked me what philosophy was, and I hadn't a clue. I still don't know! So I said, ok Tom, tell me what mathematics is. And he said, well it begins with the following axiom ... and then he had Quine's textbook, Mathematical logic, which was axiomatic. And he gave me those axioms and taught me a lot about mathematics. I enjoyed that, I spent a lot of time with Tom, when I was supposed to be working.

TM: You kept that up for a very long time.

NB: My association with Tom? Yes, I haven't seen him for several years now, and before then there was a large number of years. And I may never see him again, he lives out in the Philadelphia area somewhere. I had a trip that took me in that vicinity, so I saw him several years ago. Not likely to recur. He was really a big influence on me, and he's the one that brought me along to these international meetings that had something to do with computer languages.

TM: The trips to Europe in the '60s.

NB: He organized that for me. And I was absolutely useless on those committees. And it turns out Dana Scott was on one of the committees, and I was bowled over that he had some things to say, effortlessly. He influenced me a lot. More when we overlapped at Oxford. He gave me some stuff to read, I read his papers. I was fascinated by his lambda calculus stuff.

\section{From BA at Illinois to Grad School at Yale}

TM: Let's look at your university education more closely. The BA is from the University of Illinois. What was your subject at that time?

NB: I majored in philosophy, but in a desultory way, as I said-in a relaxed way, I didn't take it very seriously. I did it for lack of anything better to do.

TM: And was that something the family was happy with at the time? 
NB: Well ... they supported me in whatever I wanted to do, but my father would have rather I got ready for law school. I did take a couple of law courses, but they didn't suit me.

TM: It's funny, because of the meticulousness of the work you're doing. What wasn't good about law, what didn't work well with you?

NB: I don't know what to say, I wasn't really interested in anything at that time. I mean, I did my work and I got strong grades, but I really wasn't grabbed by anything until I got to graduate school, after my service.

TM: So the BA was interrupted for service?

NB: No, I was in the air force for two years, '52 to '54, but that was after college.

TM: And then you went on to graduate school at Yale?

NB: That's right.

TM: And that's when things changed?

NB: During my first year in graduate school I got interested in philosophy.

TM: Do you remember any decisive moment in that development?

NB: No. I was much taken by metaphysics and Paul Weiss, and I also studied with Arthur Pap and Henry Margenau, and that was very interesting. And I took a year long course on Whitehead which I much enjoyed, taught by Nathaniel Lawrence.

TM: That was all at Yale then. You also went on to do your PhD there. Did you have to prepare a piece of work to finish your MA, or was that course work?

NB: Course work. The MA was just after two years.

TM: And they hired you from grad school there?

NB: Well, I had a year of Fulbright in 1957-1958, studying with Canon Robert Feys at Louvain, and that's what really got me interested intellectually. He gave me an article by Ackermann to read, and that's the first time anybody had ever given me something to work on. Before that it was all course work. I worked very hard at that. Ackermann's "Begründung einer strengen Implikation", from the 1956 Journal of Symbolic Logic.

TM: So you got to read that in Europe.

NB: Yes. It's just a short article, but it fascinated me and I got interested in logic in that way. I had taken a lot of logic courses when I was at Yale, from Frederic Fitch. I must have taken about eight courses-I don't remember how many-a lot. Basic logic. I don't know if I took them all either, or whether I just sat in. But most terms I was doing some logic.

TM: With Fitch.

NB: Yes. Rulon Wells taught me my first logic course, we used Fitch's book. And that was interesting.

TM: I see when you work on something that you use that system-the method of subproofs-you have such a good way of employing it. You take out a page and then 
you write down formulae; you work from both ends and you see where you need to fill in steps.

NB: Yes, I learned that from Fitch's book.

TM: So you interrupted your time at Yale while already working on your PhD there officially, to go to Europe on the Fulbright?

NB: Yes. And I had a PhD topic but I didn't work on it at all.

TM: What was the topic?

NB: Existence-the nature of existence.

TM: We're working on that now!

NB: And then I went on to study with Feys and that's when I got interested and hooked on the academic life.

TM: And you took that back with you to Yale?

NB: Yes, I had proven something but I didn't know what it was. And I asked Feys if he knew anybody that, when I got back to the States, could help me. And he said: “Certainly, Gödel”. And I was totally intimidated. I didn't look up Gödel, but I did look up Alan Anderson. He had taught one of Fitch's lectures before I went to Belgium, and he was a wonderful teacher. I was smitten, and so when I got back I asked him whether he knew anybody who knew about Ackermann's Strenge Implikation. Alan was a very sweet man and he said (singing): "I do". I still have that image clearly. And that got us started working on what turned into the program on relevance logic.

TM: You defended your PhD at Yale in 1960 then.

NB: Sort of. It was early in 1960 that Alan said, "Why don't you write your dissertation on the stuff that we've been working on?" And I was quite surprised to learn that I could do that.

TM: Because you had been given the other topic.

NB: I thought it was cast in stone.

TM: And who was your official supervisor?

NB: Alan. Before that it was Weiss.

TM: You could transfer that, but you still thought you had to work on the old topic.

NB: I wasn't working on it, but I thought it had to be my dissertation topic. But ... I've forgotten the dates, but it was in maybe February or March, 1960, that I had this conversation with Alan, and I immediately just gathered up all the work I'd done and made a dissertation out of it. And it was effortless, I did that in six weeks. I felt very lucky, watching other people struggle. I had it all done, and it wasn't threatening-I was just having fun with Alan. We worked together very closely.

TM: And while you were working on your dissertation, you were already employed as an instructor at Yale, so you taught your first courses there?

NB: That's right, I was employed off the boat, so to speak, coming back from Belgium in ' 58 . 
TM: And then once you had defended your dissertation they made you an assistant professor there.

NB: Yes, from '60 to '63.

\section{From Yale to Pittsburgh}

TM: So you started academic life as an assistant professor in 1960, and you had lots of very good colleagues at the time. Yale was a very strong department.

NB: It was a strong department, yes. We had a strong chairman, Charles Hendel, but he left in 1959. And things started to fall apart, and stayed that way for decades.

TM: Right ... So what courses did you teach? Anderson was there to teach logic, was Fitch still around?

NB: Yes, all the time.

TM: And you were also teaching logic?

NB: Yes. But not only logic. I usually taught a general philosophy course of some kind. Not an advanced course because that was really for the older guys.

TM: And did you have many students then at Yale? How was the student population? I mean, you had grown up with them as it were, in your days as a graduate student. But you were teaching mostly undergrads?

NB: Yes, I was teaching undergraduates all the time. I didn't teach any graduate students and graduate courses at Yale.

TM: Were they different, as students, compared to the students you were together with in your days when you did your BA at the University of Illinois? Was that different, undergrads at Yale and at Illinois?

NB: I had nothing to do with the undergraduates at Illinois, so I didn't know. One of my fraternity brothers introduced me to philosophy, in a way-Jack Karns. There were people coming back from the service that were five or six years older than I was. My fraternity house was way south of the campus, half a mile or more. And Jack wanted to take this course, and he wanted somebody to walk with. And it was a philosophy course, from Max Fisch. Most of it I hadn't any clue as to what was going on, but he did have us read a little Whitehead, and I really liked that a lot. And that was the first interesting thing in philosophy that came my way. I took logic there but the logic was Cohen and Nagel, not much beyond syllogisms.

TM: That was different at Yale, with Fitch.

NB: Yes, Fitch's book was on propositional logic and quantifiers. His own inimitable system. But I had none of that at Illinois. So Jack got me interested in philosophy, I give him credit.

TM: What was your fraternity?

NB: Alpha Tau Omega. And when I graduated I entirely lost interest in the fraternity. 
TM: Over the years I've come across so many people who tell me that they got their first logic from you, that you taught them. I mean many distinguished philosophers. Did that start at Yale already? I think I remember most of the stories were about Pittsburgh. Did you have any memorable undergraduate students at Yale, with whom you kept in touch?

NB: Undergraduates ... Yes, well, kept in touch-I don't know about that. Somehow Alan wrangled me a research assistant. We had some National Science Foundation contracts and we hired undergraduates through that. Most of them came and went, but an outstanding example was Jon Barwise. He was my research assistant for one year. He was in his formative stage. We had a good time. And then there was Neil Gallagher, who didn't stay in philosophy. And John Wallace, who later went to Minnesota, was working on these NSF grants with Alan and me.

TM: You also had this grant by the Office of Naval Research.

NB: Yes (laughs). Omar Khayyam Moore, a social psychologist, had this grant from the program that the Navy had, of some kind, I've forgotten the details. But they were willing to support me for a while. That was after my dissertation was written, it paid for putting the dissertation together in a distributable form. Omar paid for that. My dissertation was on relevance logic, entailment, and was published by the Office of Naval Research, Group Psychology Branch. And I had to write some kind of preface, that one's one of my favorite prefaces actually. I wrote, I don't remember the words at all, but I remember the theme was: "It has not been conclusively proven that this material is totally irrelevant to social psychology".

TM: Self-applying the system, as it were, to the preface.

NB: Omar was a very interesting guy, and he later came to Pittsburgh.

TM: He had a position at Yale at the time?

NB: Yes. I persuaded somebody or other to move him to Pittsburgh.

TM: A lot of people were moved. So you were going along with Alan in '63, or had he left a little earlier?

NB: No, it was Wilfrid Sellars who was the person that Pitt wanted, and two of us young assistant professors, Jerry Schneewind and I, hung on his coattails to get to Pitt. And that's how I got to Pitt. I was so thrilled. I had been destined for a career consulting for the System Development Corporation, and I had actually signed up for a job with them. When I was in graduate school I went out there some summers, and I was working with Thomas Steel. He was my boss so to speak. I had met him when we were in the service, as I told you, and he was head of our unit, which was working on ciphers or codes or something like that.

TM: When you went to Pittsburgh it could have happened that you would have gone to work with the System Development Corporation.

NB: At that time it was the only job offer I had.

TM: So your initial appointment as an assistant professor at Yale was only good for two or three year?

NB: Yes, I was in my final year ... 
TM: ... but then you could join Sellars ...

NB: There was a policy at Yale, they'd see if they could reappoint you, but they declined to reappoint me. So I always said they fired me. Jerry Schneewind got an extra year, if he wanted it, but he didn't want it. And then Wilfrid brought Jerry and me to Pitt. And I was just thrilled. Adolf Grünbaum and Nick Rescher were here, they were the ones that were already here when we went. The department was a very local street car type department, and gradually we made it to international status.

TM: Absolutely. So Alan stayed at Yale for a while?

NB: Alan did. I think in '64 he went to Manchester, he had a Fulbright, working with Arthur Prior. And it was while he was there that I persuaded the Pitt people, that was the hard part, to bring him. At that time Pitt had a very loose administrative structure, it was just run by the chancellor, and there weren't any committees. There were three deans, and the point was that they had no power at all.

TM: So it was really all through the chancellor that you had to ...

NB: ... and the vice-chancellor, Charlie Peake. A great academic. And then it was a question of getting Charlie to bring Alan. That was in ' 65 . And we had been working together at Yale and we just continued working at Pitt. He died too young, in '73, that's all.

TM: That's true. So the first volume of Entailment you finished together?

NB: Yes, he had his hands on every bit of it.

TM: Your cooperation had been a bit interrupted, I guess, when he went to Europe on a Fulbright, and then because of the distance between Yale and Pittsburgh. But then you joined forces again there.

NB: That's right. Well, we had kept in close touch. We were working on things together; the way we worked when we worked together was cheek by jaw. We just sat down and wrote sentences together.

TM: I don't think it's very common for philosophers to do that.

NB: I don't think so either.

TM: But it's a very nice, very intense way of working.

NB: We had a really good time.

TM: You were hired as an associate professor, with tenure already in '63?

NB: With the promise of tenure, but not tenure. They gave me tenure, I don't know, a year later, and I was made a full professor three years later, in '66, after I'd had my six years an assistant professor.

TM: There's the Sellars Room in the Cathedral of Learning, on 10th floor. Was that Sellars's office?

NB: No. Adolf had an office on the 20th floor or something. Wilfrid's office was downstairs, 2nd or 3rd floor. A wonderful office. He was provided with a secretary and a suite, as was Adolf, and Nick. Alan and I fortunately were able to hire secretaries through National Science Foundation grants. 
TM: At that time, it's not as if you sit down and type something in $\mathrm{LTT}_{\mathrm{E}} \mathrm{X}$. It must have been truly different-lots of typewriter work.

NB: Phyllis, I remember, my first secretary — this was back at Yale—-she gave us her first page, and it was just full of mistakes, and very sweetly Alan said to her, "This won't quite do". And she never made another mistake. We were very fortunate to have secretaries.

TM: Yes, you really relied on that kind of support I suppose. Did you also share an office ever, Alan and you?

NB: No. I lived in his office, so to speak, a large part of the time. But no, we never shared an office. I had an office at Yale northerly on the campus, in a big old building, an enormous office that had a dark room.

TM: So you could do your photography.

NB: Well, sort of. I evinced interest in hooking up the plumbing, so to speak. And the next day they came and took the dark room out.

TM: Where was your office at Pitt initially?

NB: We were in the Schenley Hall. Pitt bought the Schenley Hotel and we were on the seventh floor and every office had a bathroom, a hotel bathroom. Which was terrific, because you didn't have to waste time going down the hall. My first person on the other end of the bathroom was Storrs McCall, and we worked together a lot, we had a lot of fun.

TM: So that was the time when the department was really building up to become the strong department that it then became.

NB: I neglected to mention Kurt Baier.

TM: He was there already?

NB: Yes, he was. He came a couple of years after Nick and Adolf, but before I came by a year or two. And he was chairman. A wonderful chairman he was. You hardly knew he was chairing. We had meetings in the hall. "Yeah, that's a good idea, let's do it." Not bureaucratic like it is today. And his wife Annette-those were bad times for females. She was treated very poorly for a long, long time. She got some low class employment at Carnegie Mellon University for a while, and then finally Pitt hired her back on a proper professorship. And then she thrived.

TM: How close were the ties with CMU doing all these years?

NB: They've gradually gotten closer. But they were close even then, there was a lot of back and forth.

TM: It's fortunate to have these two institutions so close together. I can see that with Kohei Kishida, for example, how well it worked out.

NB: Wonderful. 


\section{Employment History at Pitt}

TM: Let's go over the employment history at Pitt. You arrived there in '63 and you stayed there your whole career, but you wore many hats at Pitt, as it were. So the first employment was in philosophy. But a few years later you entered sociology.

NB: No, I did that right at the beginning. I taught a course that was about half philosophers and half sociologists. We had a lot fun. We all started at the beginning because nobody knew the other topic at all. It was a big seminar, about 20 people in it. That was invigorating.

TM: What would you do?

NB: Well, I read stuff, I didn't know any social science when I took the job. But I claimed I would be very pleased to teach the philosophy of the social sciences. That seemed to be a requirement for getting the job. And I had a good time doing it, I enjoyed that. I taught that for quite a few years, don't remember how many. And with these big classes of interested people. Our graduate program at Pitt was very different than it is now and has been for probably decades. We brought in about 20 students a year at the beginning. And very good ones. Bas Van Fraassen was in one of our classes. And Mike Dunn and Peter Woodruff. Bob Meyer was already there, as a graduate student-he was a hang-over so to speak.

TM: At Pitt they made you a professor of sociology in '67, a year after they made you a full professor in philosophy. And you had that job for twenty years, a joint appointment between philosophy and sociology. And then the joint appointment with philosophy of science started in 1971. Was that around the time they had a separate program in History and Philosophy of Science?

NB: It would've been about then. Larry Laudan got appointed as a member of the history department, and that wasn't going to work out. So Pitt built around him a History and Philosophy of Science department, which thrived.

TM: It's really a model, I guess, for many many other departments.

NB: Every once in a while somebody would suggest to the chancellor, Posvar at the time, that the two departments ought to be combined. And Posvar would say, "What a bad idea! Now we've got two world-class departments, and you want to make it one?"

TM: From among the hats at Pitt that you wore the named professorship stands out, named after Alan Ross Anderson, starting in 1984. How did that come about?

NB: Well, Mrs. Anderson gave quite a lot of money ... I collected as much money as I could after Alan died in 1973, I got quite a bit, but it was from graduate students and colleagues and it didn't amount to much. But then Mrs. Anderson gave a substantial amount of money, I forgot what fraction of a million. And that's how I came to be the Alan Ross Anderson distinguished professor for philosophy.

TM: And then there is another hat at Pitt: Professor in the Intelligent Systems program, what was that? 
NB: That was an Artificial Intelligence-like program. Rich Thomason came to do that. I had taught him at Yale, and he had taught me at Yale. He had been out to California and he brought back all these weird ideas about maximal consistent sets. And he taught me all that stuff, at Yale. We brought him to Pitt and kept him as long as we could.

TM: That was about the time when Pittsburgh underwent a major transformation because the steel mills were closing. And they reinvented Pittsburgh as a place for high-tech. When did the steel mills begin to close?

NB: They were closing already in the '60's. There wasn't a year in which they all closed, it was spread out. My sense of history is very poor, that's about all I can say. They were still there when I came in '63, but they were disappearing.

TM: You've spent such a long time at Pitt, there's a full page of departmental positions. Have you ever been head of department?

NB: I've once been chairman, acting chairman, 1974. But I didn't do much. I was trying to recruit Solomon Feferman.

TM: You must have been involved in many of the hires that Pittsburgh did over the years. Any notable stories?

NB: I remember hardly anything about it. The first hires-I guess Bob Brandom was in the early '70s. Myles Brand and Bob Brandom came in at that time.

\section{Visiting Professorships}

TM: You spent most of your academic life at Pitt, but you had quite a number of visiting professorships along the way, the first of which brought you to California in '73. Can you talk a little about that?

NB: That was Irvine. Irvine was recently thriving, but it was thriving. I taught there just one term, in the winter fortunately. I took my family out and we lived in Laguna Beach, they found us this wonderful house, on the beach, or close to the beach. That's mostly what I remember. I taught Bressan's General interpreted modal calculus out there, I remember that.

TM: Did you have many students?

NB: Yes, I did. I don't remember how many, but it was a noticeable number. I wasn't doing graduate teaching at Irvine, I think.

TM: Was that the time you had the motorcycle?

NB: The biggest one, yes. I started with a scooter and moved my way up. I got to California with one of those great, big ones. Somebody was willing to rent it to me for three months or something — or to sell it to me, with the agreement to buy it back.

TM: Then you spent quite some time at Bloomington, Indiana, three times.

NB: Pitt at the time was on the trimester system. They had already been on the trimester system when I came, which turned out not to succeed because people 
didn't want to go to classes for a third term. It was one of Litchfield's good ideas that didn't work out. But it did mean that I could have a trimester off. And I used that to go to teach at Indiana University in the falls of '77, '78 and '79, as I recall.

TM: Who was at Indiana at that time? Did you connect with people there?

NB: I did, my former student Mike Dunn was the principal attraction, we collaborated a lot there. I guess he's the only one I collaborated with then. But they had a lively History and Philosophy of Science department, and I spent a lot of time with them. Ron Giere was there. I organized a weekly meeting, a lunch meeting, between the two departments. And that was great. They didn't have all that much opportunity institutionally to talk to each other, so I felt I was doing a service there.

TM: And then a visiting professorship brought you to Leipzig, in 1996, the Leibniz professorship at the Zentrum für Höhere Studien.

NB: Yes, that was a wonderful term. I guess it came about because of Heinrich Wansing, who had drifted through Pittsburgh a few years earlier, and had this idea of how to do a Gentzen-style calculus, and I had worked on that quite a bit, on that style of calculus. I said "that's not going to work". And he was really bowled over. I persuaded him that it wouldn't work. So we went out and did it a different way. That was when I was developing Display logic. And then he was at Leipzig. He wasn't a man with power, but he was persuasive, I guess. I think that's how it went. Meggle was there, I did not have so much to do with him, but I saw a lot of Pirmin Stekeler-Weithofer.

TM: That must have been an interesting time there, just a few years after German reunification and the city still very much in transformation.

NB: Oh yes, there was an enormous apartment size crane on every corner. They put me on the 6th floor of a building, which was terrific. I was at first intimidated by the prospect of doing six floors, no lift, but I liked it. My classes were very small. Pirmin used to come regularly. And there were a couple of other students who came. One other from the faculty, but I can't remember who it was. It would be a class of about four.

\section{Professional Service}

TM: Let's look at your professional service. You served on the board as a program committee chairman for the Association for Symbolic Logic. And that was still during your time at Yale.

NB: It was.

TM: You also did a lot of other service to the ASL as well, right?

NB: I guess it was for about a decade.

TM: And then there is the Society for Exact Philosophy. You helped found this in the early '70's? 
NB: I was one of the founding members, but I wouldn't say I helped found it. I came to the first meeting, and I was the vice-president and president for a while, and program coordinator, etc. So in the early days I took a hand in it. We had one meeting at Pitt. It was joint Canadian/American by design, and we traded off between the two countries as to where the meetings were. It was very nice to have some close association with some Canadians, Mario Bunge for example.

TM: It was picking up the tradition of the Vienna Circle, right?

NB: Yes, the spirit was to be that of the Vienna Circle.

TM: This was the American/Canadian cooperation, but you also played a role in the British Mind Association for quite a while, as their American outpost.

NB: Alan had been the U.S. treasurer of it, which meant he kept a few funds in the bank, $\$ 100$ or $\$ 200$. Every once in a while they would ask him to pay for something. I inherited that job from Alan, for about twenty years. It was not a position of power, I payed a bill or two every year.

TM: You're also a long-time member of the American Philosophical Association. And since fairly recently, you're a member of the American Academy of Arts and Sciences.

NB: I was surprised.

TM: You were elected in 2008, together with the Coen brothers, right? I think it was the year they accepted the Coen brothers.

NB: Yes, that's right. I never met them.

TM: Any stories about the APA? Did you go to the meetings regularly?

NB: I did for a decade or two. Sometimes the Western or the Mid-Western, but mostly the Eastern. Pretty regularly. Alan and I would submit a paper, something like that. In the beginning these were smaller meetings. They could be held in a university.

TM: Now it's the job market and so it's this huge event. Did you go there, for Pitt, to hire people?

NB: Yes. But it wasn't as much fun.

\section{Journals}

TM: Let's look at journals. The earliest involvement with a journal that I find on your list is with the American Philosophical Quarterly. You were on their editorial board for over a decade.

NB: Nick Rescher was the editor and he would pass along papers for me to read.

TM: And then I think you entered the editorial board of the Journal of Philosophical Logic when it was founded. You're still on their advisory board. Were you involved in setting up the journal? 
NB: I was on the executive committee, or what it was called-the board of governors. We had meetings, frequently at Nick's office or at my office, the three of us. Gerald Massey was on the board, it was a pretty close knit group.

TM: And Pitt was running quite a number of important journals.

NB: Wilfrid Sellars was running Philosophical Studies, I don't think there was anybody else.

TM: And the Notre Dame Journal of Formal Logic was also set up around the time and you were involved with that from the beginning?

NB: I don't know what the beginning was, but it was a much less significant relationship. I had very little to do-Sobociński did everything.

TM: Then you're on the editorial board of Philosophy of Science.

NB: Today I don't do anything for these journals anymore, but some of them keep me on the masthead, I guess. I don't know which ones do or which ones don't.

TM: Studia Logica, how did that come about? I mean, that was set up in Poland.

NB: I read papers when asked to. I was never involved in the day-to-day activities.

TM: So it was really the Journal of Philosophical Logic, where your strongest involvement was, and the American Philsophical Quarterly before that. Your list also mentions the Philosophical Research Archives.

NB: I was just reading papers for the APQ, for Nick, I didn't participate in any of the administration or anything like that.

TM: You've done a lot of refereeing in your years.

NB: I have, I did a lot of refereeing. But I haven't for the last decade, or five or six years.

TM: You've done your share.

NB: That's what I tell them.

TM: Do you have a particular style that you would recommend? What should a referee do?

NB: No, I don't have any contribution to make about that.

TM: I sometimes get sent a "proof of the squaring of the circle" or something. Have you come across those things as well? Proofs that Cantor's proof is wrong? That's a favorite.

NB: The theme sounds familiar, but I don't remember any hands on activity.

\section{Prizes and Fellowships}

TM: Maybe the next thing to go over would be the list of prizes and fellowships. It starts with something pre-doctoral, from Yale.

NB: That was a book prize, I split it with somebody, money to buy books with. 
TM: And then you held a fellowship at Yale, in the year before you went to Belgium.

NB: I did, and Alan really promoted that. I didn't have a fellowship when I went to Yale. I was on the GI bill, they would pay for your graduate education as well.

TM: And then you had the Fulbright Fellowship. How did Fulbright work in those times?

NB: You wrote an application and a committee looked through the applications, and you'd sign up for which country you'd like to visit. I thought I probably wouldn't do very well in the competition and so I didn't choose any of the English-speaking countries. I knew a little French, so I chose Belgium.

TM: Any ties to Belgium? Had you been there?

NB: No. I looked it up ahead of time, and must have been talking to people, I don't quite remember. I corresponded with Feys, quite a bit. It was great. I took my wife and my two-year old, and we lived on the Chaussee de Vleurgat.

TM: In Louvain?

NB: No, in Brussels. There was no housing to be had in Louvain at that point.

TM: So you commuted by train?

NB: Yes, about twelve miles.

TM: Then, as you said, Alan helped you for the Morse research fellowship which you held at Yale, just before leaving.

NB: Yes, I had the final year off, no teaching.

TM: And then you also had a Guggenheim fellowship in '75-'76, which you preferred over another grant, from the National Endowment for the Humanities. And that was to work on Entailment?

NB: That's certainly what I was working on. It went together with half a sabbatical. I don't remember going any place, it just paid for the groceries for my family of six, at that time. And I really don't remember my application.

TM: And then you were at Stanford for a while, in 1982-83, as a fellow at the Center for Advanced Study in the Behavioral Sciences.

NB: That was my next sabbatical. One term on a sabbatical, one term fellowship, matched.

TM: And how was Stanford then? Did you interact with many people there?

NB: Not many, but Pat Suppes was there ...

TM: Was Jon Barwise there?

NB: No, but Solomon Feferman.

TM: So that's how you know him?

NB: We had tried to hire him at Pitt in 1974. He was very much underpaid at Stanford. I think we knew that he wasn't going to take the Pitt job, but we were going to facilitate his living conditions. So we had him out.

TM: And then the next fellowship I see is in 1988, from the AAAS. That was, I guess, the next sabbatical. 
NB: It must have been. It's certainly about five years later.

TM: So that's the deal you get, once every five years you get one term off and you try to match it ...

NB: Something like that. It was six terms, as I recall, at Pitt. And then one term off.

\section{Honors}

TM: Let's go over the honors. There is the Festschrift for your 60th birthday, Truth or Consequences, edited by Mike Dunn and Anil Gupta, that came out in 1990. There was a special issue of the Journal of Philosophical Logic, twenty years later. It came out in 2010, put together by Philip Kremer and Heinrich Wansing then. And at Leipzig, ten years in between, so it's evenly spaced, they made you a Doctor phil. honoris causa. So you went there for a ceremony-how as that?

NB: Oh, I enjoyed it very much! It was partly seeing old friends, and Krister Segerberg did a biographical spiel, and they played some music.

TM: You also got a Chancellor's Distinguished Research Award from the University of Pittsburgh. That went together with your visiting professorship at Leipzig?

NB: No, that was just cash. I spent it on audio-equipment for my office.

TM: How long had you had that office for, the 10th floor office? I think quite a while

NB: I couldn't tell you, we moved over to Schenley Hall, and then we moved over to the Cathedral, but I couldn't tell you what year.

TM: But that's when they gave you 1028-A?

NB: Yes. It was Kurt Baier's office that I moved into. I can't visualize myself any place else.

TM: And then there is becoming a fellow of the American Academy of Arts and Sciences, in 2008. From among these honors, is there any one that you remember especially fondly? Do you connect any of these with a feeling that you were on the right track, doing good work? Or is that more in collaborations that you got that feeling?

NB: I'm not sure what your question is, so the answer is "No", or else it's "Yes".

TM: I think what I'm trying to get at is, sometimes you work on something for a long time and then you get some external recognition for it and that helps you get a feeling of "I' $m$ doing the right thing", of pursuing a fruitful research line.

NB: I don't think my grants ever had that much effect on my self-opinion. I guess I was ... it's stupid to say, but I guess that I was confident that I was doing ok. I was gratified of course, by the various awards. I also got some kind of medal from a place in Finland; Pörn invited me there, when I was working on action theory and stuff. But I forget what it was. 
TM: You must have been in almost every European country academically, as a visitor. NB: You have the list!

TM: We'll go through the list of talks, maybe we'll have the map of Places Visited By Nuel Belnap. There is another list of grants, consultantships and research fellowships. And it starts with the National Science Foundation funding that you were talking about at Yale, in 1962-1963, for summer undergraduate research that you directed. And then the consultancy for the Office of Naval Research, on "problem solving and social interaction".

NB: Alan and Omar.

TM: That's what paid for your PhD thesis as a book. And then the next thing is your involvement with the System Development Corporation in California that you said was your job offer.

NB: I went out there in the summer for some period, as you can see for quite a few years.

TM: Was that the time that you got into computer programming, or did you have earlier experience with that?

NB: Computer programming had been my first job, in the Air Force.

TM: Oh ok, so that's how early it started really. That was in the mid 1950's.

NB: Early '50's. Very early. I graduated in '52, and then I went to Washington, worked for the NSA.

TM: "No Such Agency". What type of computers did they have?

NB: They gave us the first large-scale IBM computer, literally the size of the prototype that IBM kept. It was the first machine they sold. The NSA were about the only people who could afford it. And that was an interesting job, I really enjoyed programming. The IBM 701 had 32 instructions. One of them was a "No OP", and one of them was "Stop".

TM: Quite a lot you can do with 5 bits. How did you enter a program?

NB: Punch cards, that's how they worked.

TM: Assembler programming on punch cards.

NB: No, that was pre-Assembly.

TM: Really writing the codes for the instructions ...

NB: Yes, the actual numbers. What I remember there is that for six months we had to program in octal, and finally they gave us a way that we could program in decimal. That was just wonderful.

TM: I can imagine, it really wrecks your brain. Good training for a logician, and certainly something to make you resource-sensitive. Do you see a link with the logical systems you're interested in?

NB: No, I don't.

TM: So you had a lot of experience in computer-related work, when you went to work for the System Development Corporation. 
NB: I did, but I didn't use it for them really, although I did do a little programming, because they had a machine that I could program on. I wrote a program to test matrices. That's the only one I wrote there. Then later I wrote a program in FORTRAN to help assemble an index.

TM: That was like a standard piece of software with many people, for a long time.

NB: Well, not with many, just a few friends. That was fun too. But I did that at Pitt. I would tell you what I did for the NSA but they would shoot me.

TM: We don't want to risk that! The list of grants has quite some NSF funding, and that would give you a research assistant, or would it also buy you out of teaching?

NB: It didn't buy me out of teaching, they were summer grants as I recall. But it would get me some help, and I don't remember how that worked any more. Alan and I did all that together. Sometimes I would be the principal investigator, and sometimes I would be associate investigator. We switched roles.

TM: So that was really joint work with Alan. You were also very early in using computers in research in the humanities, in the 1960's, working with a grant from IBM.

NB: I did have a grant from them, yes. I taught a little course, there were never many people on it. We read whatever there was to read.

TM: Which wouldn't be much at that time. But it nicely goes together with involvement in philosophy of the social sciences, in a way.

NB: Sure.

TM: And then the computing story continues with the involvement in the International Federation of Information Processors.

NB: Tom Steel was head of that section, whatever the section was, "Formal description of computer languages", and he "acquired" me.

TM: And that brought you over to Europe a couple of times, for meetings.

NB: Yes ... Vienna, Sardinia, Copenhagen, ... Vienna again.

TM: And then it seems that in a similar context you spent one term at Oxford too?

NB: Yes, in my sabbatical. I got some money from them, and I was there for one term, Hilary term, in 1970.

TM: Which college were you at?

NB: Wolfson. Well, I didn't live in the college.

TM: So we're even Oxford co-collegiates. That was fairly recently set-up then, I think, Wolfson. Did you go punting?

NB: I didn't go punting. A substantial amount of bicycling, some of it in the mud.

TM: And you also spent time at the Australian National University, in Canberra.

NB: Yes, I had a term there. That was on a sabbatical.

TM: Who did you work with there? Was that the relevance logic community? 
NB: Yes, Bob Meyer was there and I overlapped actually for a couple of weeks with Mike Dunn. In Oxford I overlapped for a couple of weeks with Dana Scott, and that was very valuable to me.

TM: Did you meet him there or had you met him before?

NB: He came to my first paper, in 1963 I guess, at the University of Chicago, when I was trying to get a job. He was the only one in the audience, I think, who followed whatever I was saying. I would see him every once in a while, off and on. And of course he eventually came to CMU.

TM: You also spent some time in Moscow, at the Academy of Sciences.

NB: I did, that was a fairly short visit, in 1991, it wasn't a term or anything like that. I don't know, two or three weeks.

TM: Who did you work with there, or who got you over?

NB: I didn't work with anybody in particular. This one person, Vojshvillo, he taught at Moscow State University and he invited to one of his seminars. And I talked a little bit about whatever I was talking about at the time, but then ... there was this decision problem for the system $R$ for relevance implication. And Vojshvillo had provided a decision procedure for this, in Studia Logica in 1983. But recently my former student Alasdair Urquhart had published a proof that there was no decision procedure. Vojshvillo spoke no English but he asked me in Russian what I thought of that. And I said ... it was potentially embarrassing, but I got off without embarrassment, I said, "But look, he's my friend". That was interesting. My daughter Mary Jo came with me on the trip that time, we had a good time.

TM: To Moscow?'91 was exciting, there was lots happening ... it was really Wild West in some respects. That was in March? It must have been really cold.

NB: It was, there was ice in the streets.

TM: And in the same year then, to make up for it maybe, you stayed in Europe, or you went on to Italy, to visit Padua? In '91 it says you were a visiting professor there.

NB: Aldo Bressan invited me.

TM: So you worked with Bressan there?

NB: We talked. We didn't really do any joint projects, but we talked.

TM: And Alberto Zanardo was around at the time, was that how you got to know him?

NB: It is how I got to know him. There were two of them, Bressan's students, and I forget the other one's name, he was a physicist, who did a little work on relativity theory.

TM: There's the odd one on the list: work as a consultant for Westinghouse, that's the elevator company, right?

NB: Yes, that was a one-shot deal.

TM: So what did you do, design a new elevator brake?

NB: I gave a lecture, and I gave it on ... they didn't know what to do with me ... what they were interested in was building robotic submarines or something like that, that 
was the general topic. But I didn't talk about that, I just talked about relevance logic and how this contradiction tolerant system could be of some use. This was through a neighbor of ours in Pittsburgh.

\section{Doctoral Students}

TM: Let's go over the list of your doctor students. Those are all Pittsburgh PhD's, right? Or is there any involvement in dissertations running somewhere else?

NB: There is one down there from the University of Indiana, Daniel Cohen. The rest is Pittsburgh.

TM: It's a list with very distinguished people on it, and it nicely reflects your interests over the years. Many of those people you have collaborated with. Michael Dunn was already at Pitt when you came?

NB: No, he was, I think, in my first class.

TM: So he was quick to finish, in '66, and you only came in '63.

NB: He was. Those were the days.

TM: So you could finish a PhD in three years at that time.

NB: Well, you could. Michael took three. "The algebra of intensional logics".

TM: And then there is Carlo Giannoni, "Conventionalism in logic".

NB: He was a hold-over from the old Pitt department, as was Bob Meyer. And I took over Carlo as a kind of a charity case, so to speak, he didn't have anywhere else to go. I was never interested in conventionalism in logic. Bob of course I worked with a lot. "Topics in modal and many-valued logic".

TM: And there is Jim Carson in '69, "Logics of space and time", so that really prefigures some later day interests. Kent Wilson? "Are modal statements really metalinguistic?"

NB: Again he was a hold-over from the old department. Just being helpful.

TM: Peter Woodruff, "Foundations of three-valued logic".

NB: He dropped out of philosophy. That's philosophy's loss. A very smart guy, but he could never write anything.

TM: And then there's Dorothy Grover, "Topics in propositional quantification", and Ruth Manner, "Conditional forms: assertion, necessity, obligation and commands". Garrel Pottinger, "A theory of implications"; Alasdair Urquhart, "The semantics of entailment". So this is really a lot of work on the relevance logic project here. Jonathan Broido, "Generalization of model theoretical notions and the eliminability of quantification into modal contexts"; Arnold Vandernat, "First-order indefinite and generalized semantics for weak systems of strict implication".

NB: What he did was invent S9. I think it would have been part of his dissertation. He just published a book, recently, that came across my desk. 
TM: And there is Robert Birmingham, "Law as cases".

NB: We had a lot of fun together. Again, he did it in three years. And that was his third post-graduate degree.

TM: So he had a law background when he came?

NB: He had law background when he came and a PhD in economics.

TM: And then there is Anil Gupta, "The logic of common nouns: an investigation in quantified modal logic". Did you work together with him on the Bressan manuscript?

NB: No, that was earlier - the book came out in 1972, and Anil did his PhD in 1977.

TM: But he took your Bressan classes.

NB: And he went beyond those, yes.

TM: Glen Helman "Restricted lambda abstraction and the interpretation of some non-classical logics"; Zane Parks, "Studies in philosophical logic and its history". You told me the story of his defence, which is probably not for the record?

NB: Not for the record. Good story.

TM: There is Daniel Cohen, "The logic of conditional assertion", whom you supervised with Mike Dunn, who had already moved to Indiana. And there is Jay Garfield, "Cognitive science and the ontology of mind", that's interesting.

NB: It was interesting, he wasn't professionally interested in logic at all. We had a good time together.

TM: And then there is Jeff Horty, "Some aspects of meaning in non-contingent language", and Michael Kremer, "Logic and truth". Aldo Antonelli, "Revision Rules: An investigation into non-monotonic inductive definitions", Mitch Green, "Illocutions and attitudes", and Philip Kremer, "Real Properties, Relevance Logic and Identity". It was running in the family, the Nuel thing.

NB: I had the three of them, the father and two sons, carry my desk upstairs, that big heavy thing.

TM: Then there is Ming $\mathrm{Xu}$, who came from China to do his $\mathrm{PhD}$ at Pitt.

NB: Yes, and he stayed for much longer than planned.

TM: But now he's back, and he's big in China, right?

NB: I don't really know how big he is, it's a little hard to judge.

TM: Well, China is so big.

NB: Yes.

TM: There is Stephen Glaister, "Belief revision". And John MacFarlane, "What does it mean to say that logic is formal"-you were on the committee but he wasn't officially your PhD student? And then you have to add Kohei Kishida, "Generalized Topological Semantics for First-Order Modal Logic".

NB: That's correct.

TM: That's quite a list. A few of those finished in three years, but some hung on for a lot longer ... 
NB: As you get later, they get longer.

TM: So who is the longest?

NB: Zane, I guess. He wrote several papers, among them a nice one in Journal of Philosophical Logic, in '72.

\section{Publications}

TM: One more list to go: Let's go over your publications. I'm of course very happy about that publication list because it got me the Erdős number 3, through your 1967 paper with Spencer, who later wrote a book with Erdős.- The first paper, from 1955 , is influenced by Weiss?

NB: I guess so, I always debated whether I should put that on my list of publications or not. I hope nobody looks it up. I don't think anyone can find it.

TM: We'll try.

NB: I don't think I want you to try.

TM: And then the first real paper already made into the Journal of Symbolic Logic immediately, in 1959. It's an abstract, right? A two-page abstract on Ackermann's Strenge Implikation.

NB: There's the paper a year later, it's called "Modalities in ..." instead of "A modification of Ackermann's 'rigorous implication'".

TM: That's then the real paper, but you reported the result before. And then there is a technical report that appears in Zeitschrift für Mathematische Logik. And then in 1960, lots of things in JSL and technical reports for your grant, with the Office of Naval Research.

NB: And reviews of some kind or another. A book note.

TM: On Pat Suppes's Axiomatic set theory. And most of your formal-logical publications are co-authored with Alan Anderson.

NB: Indeed.

TM: Most of that material made it into the book, Entailment?

NB: Yes, probably all of it. We didn't want to throw anything out.

TM: Tell me about the "simple proof of Gödel's completeness theorem" in JSL 1959 ?

NB: It was just ... instead of Gentzen consecutions you just add disjunctive formulas and did the obvious thing. I mean unending disjunctions. We were anticipated with that format though by Schütte.

TM: We see you doing your job writing book reviews for the Review of Metaphysics, for the $J S L$... then there is "Entailment and relevance". And then there is the metalogical paper, "Tonk, plonk and plink", in reply to Prior's "Runabout inference ticket". That's a nice piece. 
NB: An afternoon's piece.

TM: It started something, right?

NB: It has a lot of credit that it doesn't deserve.

TM: Why do you think so? There are some very original ideas in there.

NB: It's sloppy.

TM: It was good enough for Analysis ... Then there is a paper on intuitionism with Hugues Leblanc. How did that come about?

NB: I forget. It was a supervaluational paper of some kind. We had some kind of result about what you could do in which notation or something. It was mostly Hugues's paper.

TM: And there is more work building up to Entailment, and then there is the first paper on your work on questions, for the System Development Corporation. Is that the nucleus for the later book, The logic of questions and answers?

NB: Yes indeed.

TM: How did that crop up out of your consultancy work?

NB: Well, when I went out there I was afraid they were going to assign me some project. So I decided to bring a topic with me. I had read this little paper of David Harrah's, "A logic of questions and answers", and I said I'd like to work on that, and they said "fine".

TM: And then you had to write a report.

NB: A few years later, yes.

TM: There's more book reviews, and another paper with Hugues Leblanc and with Rich Thomason on intuitionism.

NB: We met in a hotel room in New York and worked that out.

TM: And then there is more reviews and more work on Entailment, and also a Journal of Philosophy paper on "Questions, answers and presuppositions" in 1966. That's early, I guess, for formal work on presuppositions. How did you get to work with the notion of presuppositions?

NB: It was already in the book. The book hadn't come out yet, but it was already in my earliest research, the simple logical ideas.

TM: Ask a stupid questions and get a stupid answer, the main theorems, I remember that.-And then in ' 67 we have the item that makes the link to Joel Spencer, later a coauthor of Paul Erdős's.

NB: Yes. This was when he was an undergraduate, in '67. We recruited him on one of these National Science Foundation support schemes. In the summer, or some part of the summer.

TM: And you wrote this up and he went on into mathematics from there.

NB: Yes, on to the Courant Institute.

TM: So we're in 1967 ... A lot of the foundational work for Entailment is still going on. There is a reprint of your piece on "Tonk". And then there is work on distributive 
lattices by you together with Michael Dunn. And a longer outline of Entailment with Alan. There is also work on the substitution interpretation of the quantifier by you and Mike Dunn. I'm just going over these thing, and whenever you want to comment ... NB: For a while Lennart Åqvist and I had a kind of dog-and-pony show. He would read a paper at one conference and I would read one on the next.

TM: Was he in the U.S.?

NB: He visited, yes. I don't remember, I think he was there for a term or what. They didn't treat him well.

TM: At Pitt?

NB: No, in Scandinavia, in Sweden.

TM: There's another piece on questions, in this nice volume The logical way of doing things edited by Karel Lambert. There is a lot of Pittsburgh in that volume. And there is a result that you published with Storrs McCall, in 1970, "Every functionally complete $m$-valued logic has a Post-complete axiomatization". In 1970 there is another piece which I think builds up to The logic of questions and answers? The piece on "Conditional assertion and restricted quantification"?

NB: No. Conditional assertion was a separate project. And restricted quantifiers was a quantified version of that.

TM: And then in '71 all you do is write a review, but you prepare Bressan's manuscript, right?

NB: I don't know what I was doing.

TM: But around that time you must have been working on getting that manuscript published.

NB: One might hope so.

TM: Because then in ' 72 the book, Bressan's General interpreted modal calculus comes out, with your preface, and I'm sure it would never be there, but for your work on this.

NB: I suppose that's true. My contribution was really minor even given that. No logical contribution at all.

TM: I guess you would have clarified a few things in the manuscript.

NB: I don't think so. I don't remember, but I don't think so. I was just translating from Italian into English.

TM: Well.- There is joint work with Dorothy Grover, in 1973, and this is connected with the project of the prosentential theory of truth already?

NB: Yes.

TM: And there is another piece on conditional assertion ...

NB: ... and restricted quantification. I forget what the difference is between those two papers. I hope there's a difference.

TM: Well this is in a book, and the other is in a journal. And then there is a Journal of Philosophical Logic paper on interrogatives. And then, was it in ' 73 or ' 74 that Alan died? 
NB: Would have been '73.

TM: Then you have your long piece on the prosentential theory of truth in Philosophical Studies, in which you tell the nice story of how it got in there, despite its length. I think that's also one of the papers that many philosophers have read, because it's not very technical.

NB: I think, I don't know if it's read anymore, but it was read for a long time.

TM: I think it's being reprinted. And then you have the "Useful four-valued logic".

NB: That was really with malice aforethought. I worked out that title, and the reason is that it sounded so pretentious that I thought people would think there was a topic there that they should deal with. It didn't look just like a result.

TM: But that's what it is, useful, right, the title is descriptive.

NB: Yes, that's fair. I tricked them into reading the paper and all.

TM: And Ryle was there?

NB: He was there! Did I ever tell you about that? He came and congratulated me, he said that was the best paper he ever heard ...

TM: There you go! That's a real best paper award I think.--In 1975 you finished Entailment, Volume 1. It was already announced as Volume 1, because there was such a large body of material.

NB: Yes there was. Princeton University Press was quite reluctant to let us have that title because they were afraid we would Church them.

TM: Oh, that's how you can use "to Church". That has happened, indeed, with the Introduction to mathematical logic. But you didn't.

NB: We didn't. It took fifteen years but we didn't.

TM: Then here is a result on the piece of software you wrote for the System Development Corporation.

NB: Yes. I don't know what I wrote it for.

TM: It's about testing matrix-claims. So this is really about logical matrices?

NB: It's a trivial paper, I wouldn't say it's about logic at all. I didn't remember what the spiel was of that article.

TM: And then you have the next book appearing, with Thomas Steel, The logic of questions and answers. There's really lots of books appearing. That was translated into Russian, later on?

NB: Yes.

TM: So that's '76. Can you say something about "The two property", in The relevance logic newsletter? Or maybe about the newsletter?

NB: Oh, the newsletter was just a very small publication that existed for a few years. The two property was simply that all the theorems had to have an even number of variables. It had to do with a little fragment; I had conjectured that its only theorem was $A \rightarrow A$, including fat formulas, but always $A \rightarrow A$. 
TM: And then there is "How a computer should think", in 1977, which is the first paper on the useful four-valued logic?

NB: I don't know, first or second, there were two of them.

TM: Yes, because then there's the paper with the title "A useful four-valued logic".

NB: I put those together for the book.

TM: And there is an abstract with Michael McRobbie.

NB: Currently the president of Indiana University.

TM: There you go. Succeeding Mike Dunn, or how is this?

NB: No, Michael was never president.

TM: But he had some higher office there as well?

NB: He was the Dean of Informatics. He attracted McRobbie.

TM: So we're in 1978 and your book indexing software BINDEX gets published. And then in ' 79 your piece with McRobbie that you had reported on, on tableaux for relevance logic, was published. And then more work that builds up towards the second volume of Entailment, I guess? "A consecution calculus for positive relevant implication with necessity".

NB: That was for Volume two.

TM: And then there is a piece on the development of modal and relevance logics in Agassi's Modern logic, from 1980: "Modal and relevance logic: 1977".

NB: They didn't like it that I put the year on it, but I insisted.

TM: What is it about the year?

NB: That's how far my little history went.

TM: And then, even though they dismantled your darkroom, you still got a photograph published in Haugeland's book, Mind design.

NB: I did.

TM: What's on the photo actually? I never looked it up.

NB: It's the head and shoulders of John Haugeland.

TM: Then there is an application of your logic of questions and answers in the Montague grammar project, and a piece on teaching logic and relevance logic.

NB: I don't remember how that came about either.

TM: "Logika voprosov i otvetov".

NB: That was at a conference or meeting.

TM: So there are some Russian translations of your work, by Smirnov. And then there is display logic. So was Heinrich Wansing already around, had you met him back then in ' 82 when you published your first work on display logic?

NB: I don't remember, I'd certainly done the work before I met with Heinrich.

TM: And then the paper on "Gupta's rule of revision theory of truth", that became the nucleus for your joint book with Anil Gupta, on the revision theory of truth? 
NB: Although I am listed as a co-author of The revision theory of truth, it was really Anil's book.

TM: Then there are papers on the semantics of questions, this is in the linguistics community, right? With von Stechow as one of the editors. And then there is an abstract on display logic in JSL, and there is more work for the second volume of Entailment. And more work on the semantics of questions. And then you have a joint paper with Anil in 1987, in the Journal of Philosophy: "A note on extension, intension, and truth". It's quite noteworthy for a paper with a logic focus to appear there?

NB: I guess, I don't remember. It was largely Anil's paper.

TM: And here's another book you brought to life, Charles Hamblin's Imperatives, in 1987. You did the editing on that one as well?

NB: No, I just wrote the foreward.

TM: That's an important book.

NB: I think it is, yes. Though it's not much read today.

TM: You put it on the list of required reading for Facing the future.

NB: That's right!

TM: And then there is a German translation of the prosentential theory of truth paper, in Der Wahrheitsbegriff, edited by Lorenz Puntel. And then 1988 sees the first paper in the "seeing to it that" program, stit, with Mickey Perloff. And then there are many more papers in that line to come. But also the relevance logic program is going on: You write for the Directions in relevance logic volume edited by Norman and Sylvan. And then in 1990 you have a paper with Gerry Massey, on semantic holism. How did that come about?

NB: He brought me a logic problem of some kind and I solved it. But he wrote up the stuff about the history-he put in a kind of medieval historical context, with lots of scholars doing something or other. It was nice what he did.

TM: And there's a paper, also in 1990, “Declaratives are not enough". I think I've never read that, a shame.

NB: Not really. It's just a kind of a rehash of taking questions and imperatives seriously.

TM: There is further development in the display logic program. And a second paper on stit by you and Mickey. And in the year after, 1991, a paper that you authored for Erkenntnis, on the same topic, "Before refraining: concepts for agency". And also in the first DEON workshop, Deontic logic in computer science, you had a paper on stit. You seeded it into the computer science community very early. I think of DEON as a computer science conference mostly. So Jean-Jules Meyer and Roel Wieringa edited that. In 1992 there is more on developing stit-theory.

NB: And twenty years later people start reading that paper!

TM: Good for them!- If you have an annus mirabilis, it's 1992? There is "Backwards and forwards in the modal logic of agency", in Philosophy and phenomenological 
research. Also the second volume of Entailment comes out, and your "Branching space-time" paper appears in Synthese. How long had you been working on that?

NB: I had been working on it for several years, I'm sure. But memory dims.

TM: And it's really an outgrowth of the stit-project, in a way.

NB: It is.

TM: I learned this very late, because I didn't connect initially, but it makes perfect sense, of course. It's all about causal independence and how you model that.

NB: Exactly.

TM: Moving on, in '93 there is the book with Anil Gupta, on The revision theory of truth, and also you're promoting stit with Mickey Perloff. And I guess in connection with the work on circular definitions for the revision theory book, there is your paper "On rigorous definitions"?

NB: No, that was entirely separate. I mean, this paper mentions circular definitions in about a paragraph at the end. But mostly it's just ... the literature on rigorous definitions is so poor, I thought I wasn't going to interfere with anyone by adding. I shouldn't say poor, but thin.

TM: I think our Utrecht PhD student Sebastian Lutz was able to make good use of that. And then there is your paper with Mitch Green, "Indeterminism and the thin red line", which is a classic, I guess.

NB: In certain circles.

TM: The circles are growing. And the next paper is on substructural logics.

NB: "Life in the undistributed middle". I tried to find that paper, I guess yesterday or the day before, but it's not accessible from where I am.

TM: And there is a paper on analytic tableaux, for linear logic is that?

NB: Yes.

TM: And more work building up toward Facing the future. There is also the other approach to stit, deliberative stit rather than the achievement stit, with Jeff Horty, in a paper for the Journal of philosophical logic, 1995. And a piece in the Festschrift for Ruth Barcan Marcus. Did you know her well?

NB: Academically, but pretty well. Over a lot of years. I have always felt affection for her.

TM: Unfortunately I never met her, I think she had some very good influences. So there is a paper on "The display problem" in a volume on proof theory that Heinrich Wansing organized. And then the second paper on BST, "Branching spacetime analysis of the GHZ theorem". This was when the Hungarians came to invade Pittsburgh, László Szabó and Miklós Rédei.

NB: That was not a good paper.

TM: Well, I think it was really an important step. And then you went to the Prior memorial conference, there is a paper on "Agents in branching time" in the proceedings volume, edited by Jack Copeland. It may actually be that this is the first time that 
I saw your name, something around that time, because I had looked at that volume. And there is a paper on "The very idea of an outcome"; the notes connected to that paper, I think, brought Tomasz Placek into BST.

NB: That's right.

TM: Then here is work in '97 building up to the deontic part of Facing the future. Did you have the idea of wrapping that all up in a book by then? It must have been at around that time.

NB: It must have been. Mickey and I had the idea fairly early, that we were writing chapters of a book.

TM: And you were getting them out as articles. There is another dstit paper with Jeff Horty; he had his book out in the same year as Facing the future. And there is this very nice paper on "Concrete transitions" in '98, digging out this notion of a transition in von Wright, which is not easy to find in his work, I think. Did he react to the paper?

NB: I don't think so. I read it at his conference, yes. But I don't recall that he had anything to say about it.

TM: In his work, transitions are really buried in the idea of "and next", which is much less subtle then what you make of it. "Truth by ascent", from 1999, I think I haven't read that. What's in there?

NB: Intimations of the revision theory.

TM: And then this is a piece that I guess will be very hard to find, "Modest notions of free will and indeterminism", in the Proceedings of the Creighton Club, 1999-but it's one of the few pieces in which you say something about the role indeterminism can play for us.

NB: It comes out in some other papers.

TM: Yes, it does. Then 2000 has the invited paper to the Advances in Modal Logic conference in Leipzig. This is your piece on "Double time references: Understanding speech-act modalities in an indeterministic setting". So this is, as it were, maybe the next step in the (anti-)Thin red line project. And then in 2001 we have the book, Facing the future, together with Mickey Perloff and Ming $\mathrm{Xu}$. You did the typesetting for that all by yourself?

NB: Yes.

TM: I think most of the following items I know pretty well. With an intermission of a couple of years, there is the next paper on applying the branching space-times ideas and working out one of the central notions in the BST-framework, namely the idea of modal correlations, or as you call it, "funny business". And that's when we met, at the Workshop on non-locality and modality in Kraków in 2001 that Tomasz Placek organized with Jeremy Butterfield. Can you say something about the period in between, from 1992 when BST appeared, until that paper? What made you pick up this idea again? It seems like in the late '90s most of your work is really on what becomes Facing the future, and BST is not part of that. But it's of course clear in a 
sense that BST is going to be the next step. It's interesting that it wasn't on the map for a number of years, and then it becomes really big after ten years.

NB: I don't remember how that went.

TM: The next paper continues the analysis of funny business, "No-common-cause EPR-like funny business in branching space-times", in Philosophical Studies, 2003. And then there is your paper from the trip to Guangzhou, China, "Agents in branching space-times". And a paper on non-classical logics from the same trip, right?

NB: Just so.

TM: And then a similar paper, "Agents and agency in branching space-times", appears in Daniel Vanderveken's volume, Logic, thought and action, in the book series Logic, Epistemology, and the Unity of Science. And then, for me this is maybe the most important paper, the "Causae Causantes" paper in the British journal for the philosophy of science from 2005.

NB: I think it's one of my most important papers. It will take another twenty years before anybody reads it ...

TM: But then it will have been there, sitting there for people to discover. I think it's great, it's really a masterpiece, a very good paper. It did a lot with me. And then there is your paper with a biographical title, "Under Carnap's lamp", written under Carnap's lamp. The lamp is now in Konstanz, you gave it to their archive, right?

NB: Yes.

TM: And there was some ongoing work on BST; you worked with Matt Weiner in the '90s, Matt had some results and he added a postulate about the relative ordering of suprema of a chain, and there are ideas about building up a probability calculus in BST. You wrote this up and put it together into a nice form, "How causal probabilities might fit into our objectively indeterminsitic world", Synthese 2006.

NB: Yes.

TM: And in the Festschrift for Hugues Leblanc in 2005 there is a paper on a "Branching histories approach to indeterminism and free will", one of the other places where your approach to free will comes to the fore.

NB: Yes, and I think this has some of the one we passed over on free will ...

TM: ... the Creighton Club ... What I find fascinating now going over this list, which of course I've looked at before, is to see how long some of the lines are that you draw, within your work. Because in 2006 we really have the first paper on Bressan. That's almost 35 years after having brought out the book. I think, we take this list, and we go to the University administrators and we tell them, "You see, this is how research goes".

NB: Give it time!

TM: You don't throw everything overboard every three years! The 2006 paper is a nice piece-extremely useful, I think, for making Bressan accessible.

NB: I'm disinclined to think that, I think that what you and I are working on now is making Bressan accessible, but I don't think the 2006 paper does much ... 
TM: Well, we will see. Then there is "Prosentence, revision, truth and paradox", in Philosophy and Phenomenological Research in 2006-again, picking up an earlier topic.

NB: That was, I think, something having to do with Tim Maudlin's book on truth. I'm not quite sure I remember. It was an occasional piece anyway.

TM: Ok, so the next one, 2007 ... we're almost done. This is the piece on "Propensities and probabilities", in Studies in History and Philosophy of Modern Physics, that you wrote for the proceedings of the 2005 Kraków workshop on branching space-times.

NB: Tomasz Placek found so many mistakes in it.

TM: But there is a new version of it. And there is this very nice piece motivating BST, that you so kindly wrote for the Stuhlmann-Laeisz Festschrift that I edited, which is now also out in an updated form in Synthese 2012. And also a very nice piece on parameters of truth for my little book on time, Philosophie der Zeit. And I remember very fondly, of course, the paper that we published with Kohei Kishida, on "Funny business in branching space-times: infinite modal correlations". And then the written list stops, but we know that there is a lot more, of course, and a lot more to come. There is all your work on topological issues in BST, from the collaboration with Tomasz Placek, and recently, our joint work on "Case-intensional first order logic"; your contribution to this book, on internal cases, is part of that enterprise, which is continuing.- Thanks, we've done the full list of publications!

NB: Have we!

TM: What's the most important paper? I guess, by your reactions to it, the Causae Causantes paper from 2005 is one candidate ...

NB: I think so.

TM: The "Useful four-valued logic" paper from 1978 is another one?

NB: That's been a very popular paper. Probably the most read paper, but I don't know important it was.

TM: Thanks, Nuel.

Open Access This chapter is distributed under the terms of the Creative Commons Attribution Noncommercial License, which permits any noncommercial use, distribution, and reproduction in any medium, provided the original author(s) and source are credited. 